\title{
Leukokinetic Studies
}

\author{
XIV. BLOOD NEUTROPHIL KINETICS IN CHRONIC, \\ STEADY-STATE NEUTROPENIA
}

\author{
C. R. Bishop, G. Rothstein, H. E. Ashenbrucker, and J. W. Athens \\ From the Department of Medicine, Veterans Administration Hospital, and \\ University of Utah College of Medicine, Salt Lake City, Utah 84112
}

A B S T R AC T The kinetics of blood neutrophils was investigated by means of the in vitro radioactive diisopropyl fluorophosphate method in 35 patients with a chronic, steady-state neutropenia. There were 17 patients in whom the half disappearance time of neutrophils was normal. In 10 of these patients, the production of neutrophils was low and in 7 , production was normal. In 18 patients the half disappearance time of neutrophilic granulocytes was shorter than normal. The production of neutrophilic granulocytes was low in five of these patients, normal in eight patients, and increased in five. An attempt was made to correlate other laboratory measurements with the kinetic picture, but no relationship was found; the marrow neutrophil reserve as measured by endotoxin or cortisol injection; marrow cellularity on aspiration or biopsy; in vitro-labeling index with ${ }^{3} \mathrm{HTdR}$; or serum lysozyme concentration proved of no value in identifying the various kinetic groups. The only finding that seemed to correlate with the kinetic picture was the presence or absence of splenomegaly. In 12 of the 18 patients with a short half disappearance time, splenomegaly was present whereas in 15 of 17 patients with a normal half disappearance time, there was no splenomegaly. Of 20 patients with greater than 1000 neutrophils per $\mathrm{mm}^{3}, 17$ were found to have a normal total-blood neutrophil pool. Thus these patients, with many of their cells marginated, agree to have a "shift neutropenia."

Myelocyte to blood transit time and myelocyte generation time, as measured in seven patients by in vivo labeling with diisopropy fluorophosphate, proved to be essentially normal. Thus, it appears that in chronic neutropenia, increased or decreased production of neutrophils is accomplished by increasing or decreasing early precursor input into the system.

Received for publication 15 October 1970 and in revised form 8 February 1971.

\section{INTRODUCTION}

Using $\mathrm{DF}^{32} \mathrm{P}$ (diisopropyl fluorophosphate) ${ }^{1}$ as a labeling compound, it is possible to measure the size of the total blood neutrophil pool (TBGP), the circulating neutrophil pool (CGP), and the marginal neutrophil pool (MGP) as well as the blood-neutrophil half disappearance time $\left(t_{\frac{1}{2}}\right)$. From the $t_{\frac{1}{2}}$ and the TBGP, the neutrophil turnover rate (GTR) can be calculated. This is a measure of effective neutrophil production rate.

Such leukokinetic studies have defined normal neutrophil kinetics $(1,2)$. The kinetics of neutrophilic granulocytes in a number of disease states with associated neutrophilia has also been characterized.

To assess the kinetic patterns of neutrophils in neutropenic states, 35 neutropenic patients were studied by means of the $\mathrm{DF}^{32} \mathrm{P}$-neutrophil kinetic method. In addition, a correlation between the kinetic results and a variety of clinical and laboratory findings was sought in the hope that an easy method of identifying the kinetic categories might be evolved. Some of these results have been reported previously (3-6).

\section{METHODS}

35 patients with neutrophil counts of 1830 cells $/ \mathrm{mm}^{3}$ or less were selected for study. However, because of fluctuation in neutrophil concentration in some of these patients, the blood neutrophil concentration was greater than 1830 cells $/ \mathrm{mm}^{3}$ on the day of study. Nevertheless, such patients were included as neutropenic patients, since they were clearly neutropenic during most of the observation period, both before and after the kinetic studies.

All subjects were in a steady state at the time of study. Only patients with neutrophil counts greater than $125 / \mathrm{mm}^{3}$ could be studied.

${ }^{1}$ Abbreviations used in this paper: BGSA, blood neutrophil-specific activity; CGP, circulating neutrophil pool; $\mathrm{DF}^{32} \mathrm{P}$, diisopropyl fluorophosphate; GTR, neutophil turnover rate; MGP, marginal neutrophil pool; TBGP, total blood neutrophil pool. 
After explanation of the proposed studies, all subjects consented to measurement of the size of the total-blood neutrophil pool (TBGP), circulating neutrophil pool (CGP), marginal neutrophil pool (MGP), half disappearance time $\left(t_{\frac{1}{2}}\right)$, and neutrophil turnover rate with the in vitro $D^{32} \mathrm{P}$ method (2). ${ }^{2}$

Blood leukocyte concentration was measured by means of a Coulter Counter (Coulter Electronics) using a modification of the cetrimide-citrate lysing diluent (7). At least 200 cells were counted on cover slip smears (Wright's stain) and absolute cell concentrations were calculated from this differential cell count and the blood leukocyte concentration. In our laboratory, the normal blood neutrophil concentration is $1,830-7,250 / \mathrm{mm}^{3}, 95 \%$ limits (8).

As in previous neutrophil kinetic studies (2), the "determined" TBGP was calculated from the mean neutrophil radioactivity of two or three blood samples obtained 5-10 min after completion of the infusion. Also, as in previous studies, three types of blood neutrophil radioactivity curves were observed: (a) a single exponential blood neutrophilspecific activity (BGSA) curve, designated type "A" curves in the Tables; $(b)$ an initial rapid fall in BGSA during the first $3 \mathrm{hr}$ followed by a single exponential disappearance curve thereafter, designated type " $B$ " curve in the Tables; and $(c)$ a slurred curve (convexity downward) in which the $t_{\frac{1}{2}}$ was continually changing and could only be approximated as less than some maximal value, designated " $\mathrm{C}$ " curves in the Tables. The blood neutrophil-radioactivity values were measured either as counts per minute per milligrams of neutrophil nitrogen, or as counts per minute per $10^{7}$ neutrophils.

A few patients were also studied by means of the in vivo $\mathrm{DF}^{32} \mathrm{P}$-method in which DFP was injected intravenously $(9,10)$. In these studies, the complex, triphasic curve was plotted on semilogarithmic graph paper and the best line depicting each phase was fitted to the data points by means of least squares. The duration of phase I + II was taken as a measure of the transit time through the marrow neutrophil reserve. The $t_{\frac{1}{2}}$ of phase III was taken as a measure of myelocyte generation time $(3,9,10)$.

Serum lysozyme levels were measured by the lyso-plate method described by Osserman and Lawlor (11). Values are expressed as micrograms per milliliters and were read from a standard curve prepared from known dilutions of egg-white lysozyme (Difco Laboratories, Inc.).

Neutrophil mobilization capability was measured after cortisol or endotoxin injection as follows: after obtaining a control blood cell concentration, $200 \mathrm{mg}$ of hydrocortisone phosphate ${ }^{8}$ was injected intravenously over a 5 min period. Over the next $6 \mathrm{hr}$, hourly blood samples were obtained for measurement of leukocyte concentration and a differential cell count. The absolute neutrophil concentrations were plotted on arithmetic graph paper and the maximal change in neutrophil concentration $(\Delta \mathrm{N})$ expressed as the peak value minus the control, was recorded.

Endotoxin studies were identical to the cortisol studies except that $8 \mu \mathrm{g}$ of Piromen ${ }^{4}$ was injected intravenously to stimulate a neutrophil response.

\footnotetext{
${ }^{2}$ Since DFP labels only neutrophilic granulocytes and not eosinophils or basophils the terms granulocyte and neutrophil have been used interchangeably in the past. TBGP, CGP, and GTR are retained here for the sake of continuity with prior publications on this subject.

${ }^{3}$ Kindly supplied by Dr. E. Alpert of Merck Sharp \& Dohme, West Point, Pa.

'Kindly supplied by Flint Laboratories, Morton Grove, Ill.
}

Bone marrow studies. Marrow samples were obtained by aspiration from the sternum or posterior ileum and cover slip smears were prepared and stained with Wright's stain. In some patients, a needle biopsy with a Vim-Silverman or Westerman-Jensen needle was obtained as well. A differential cell count ( 500 or 1,000 cells) was done on the thin smears and the general morphologic picture and cellularity was estimated in the biopsy specimens.

In addition, $0.50-1 \mathrm{ml}$ of aspirated marrow was added to $1 \mathrm{ml}$ of TC-199 culture medium (3) which contained 0.1 $\mathrm{mg}$ of dried heparin ${ }^{5}$ and $2.5 \mu \mathrm{Ci}$ of tritiated thymidine (thymidine-methyl ${ }^{3} \mathrm{H}, 1.9 \mathrm{Ci} / \mathrm{mm}$ ). This cell suspension was gently mixed every $10-15 \mathrm{~min}$ for $1 \mathrm{hr}$ at $37^{\circ} \mathrm{C}$ and then centrifuged at $280 \mathrm{~g}$ for $10 \mathrm{~min}$ at $4^{\circ} \mathrm{C}$. The supernatant was discarded and the cell button resuspended and washed in $1 \mathrm{ml}$ of the patient's serum. After recentrifugation, the supernatant was again discarded, the cells were resuspended in several drops of serum and thin smears were prepared on cover slips. After fixation with methanol, the cover slips were mounted on glass slides and autoradiographs prepared using Kodak NTB-3 dipping film. The films were developed after a $24 \mathrm{hr}$ exposure period and stained with Kingsley stain at $\mathrm{pH} 5.45$ (12). The proportion and type of myeloid cells labeled was determined for 500 myelocytes from each subject so studied.

Uric acid excretion per $24 \mathrm{hr}$ was determined by the enzymatic method (13).

\section{RESULTS}

\section{Blood neutrophil production and turnover in chronic steady-state neutropenia}

From a kinetic point of view, neutropenic patients can be categorized into those with a normal blood neutrophil $t_{\frac{1}{2}}$ value and those with a short $t_{\frac{1}{2}}$ value. In the present study, 17 patients fall into the normal t category (Table I) and 18 into the short $\mathrm{t} /$ category (Table II). The patients in these categories can be further divided into groups on the basis of whether blood neutrophil production (GTR) was normal, decreased, or increased.

\section{Neutropenia Characterized by a Normal $\frac{1}{2}$}

The results obtained in the 17 patients with a normal $\mathrm{t}_{1}$ are presented in Table $\mathrm{I}$; two patients with slightly long $t \frac{1}{1}$ values are included in this category.

Effective neutrophil production was less than normal, as measured by the GTR, in 10 of these patients and this appears to explain their neutropenia (Table I-A). In two of these, marrow suppression by drugs was clearly documented (Cases 6 and 7) and in two others, untreated acute leukemia in relapse appeared to explain the decreased neutrophil production. In the remaining six patients, the cause of the neutropenia was not clear. In only 1 of these 10 patients was splenomegaly noted. Measurement of the TBGP in subject 3 resulted in a smaller value than the CGP, an impossible result. There would seem to be less error in measuring the CGP and

\footnotetext{
${ }^{5}$ Panheprin, brand of sodium heparin, Abbott Laboratories.
} No preservative added. 
TABLE I

Neutropenic Patients with

\begin{tabular}{|c|c|c|c|c|c|c|c|c|c|}
\hline \multirow[b]{2}{*}{ Subject } & \multicolumn{7}{|c|}{ Kinetic data } & \multicolumn{2}{|c|}{ Clinical data } \\
\hline & $N$ & TBGP & CGP & $\begin{array}{l}\text { CGP/ } \\
\text { TBGP }\end{array}$ & $t_{1}$ & GTR & $\begin{array}{c}\text { Curve } \\
\text { type }\end{array}$ & $\begin{array}{l}\text { Spleno- } \\
\text { megaly }\end{array}$ & Diagnosis \\
\hline & $N / m m^{3}$ & \multicolumn{2}{|c|}{$N \times 10^{7} / \mathrm{kg}$} & & $h r$ & $\begin{array}{c}N / k g \text { per } \\
d a y \times 10^{7}\end{array}$ & & & \\
\hline \multicolumn{10}{|c|}{ Normal values $f$} \\
\hline \multicolumn{2}{|c|}{ Mean .... } & 61 & 31 & 0.49 & 6.3 & 160 & & & \\
\hline $95 \%$ & hits & $27-138$ & $13-49$ & $0.2-1.0$ & $4-10$ & $62-400$ & & & \\
\hline
\end{tabular}

Neutropenic patients with normal $t_{\frac{1}{3}}$ and decreased cell production (GTR)

$\begin{array}{rrrrrrrrll}1 & 881 & 11.0 & 5.6 & 0.51 & 6.0 & 30 & \text { Irreg. } & - & \text { Idiopathic } \\ 2 & 294 & 8.8 & 2.9 & 0.33 & 5.9 & 25 & \mathrm{C} & - & \text { AML, no Rx. } \\ 3 & 985 & 1.8 & 8.8 & - & 5.3 & 6 & \mathrm{~A} & - & \text { Idiopathic } \\ 4 & 1342 & 9.8 & 9.1 & 0.93 & 4.3 & 38 & \mathrm{~A} & - & \text { Idiopathic } \\ 5 & 481 & 3.5 & 3.5 & 1.00 & 3.8 & 16 & \mathrm{~A} & - & \text { AML, no Rx. } \\ 6 & 1159 & 27.4 & 10.3 & 0.38 & 8.0 & 57 & \mathrm{~A} & - & \text { MM on melphalan } \\ 7 & 530 & 13.2 & 4.2 & 0.38 & 6.3 & 15 & \mathrm{~B} & - & \text { Butazolidin } \\ 8 & 2172 & 21.8 & 15.9 & 0.73 & 6.7 & 54 & \mathrm{~B} & - & \text { DLE } \\ 9 & 1603 & 29.6 & 13.6 & 0.46 & 11.0 & 41 & \mathrm{~B} & + & \text { Cirrhosis } \\ 10 & 663 & 31.0 & 7.8 & 0.25 & 12.0 & 50 & \mathrm{~B} & - & \text { ? Familial or drugs }\end{array}$

Neutropenic patients with normal $t_{\frac{1}{3}}$ and normal cell production (GTR)

$\begin{array}{rrrrrrrrll}11 & 2015 & 37.2 & 12.8 & 0.34 & 6.5 & 95 & \mathrm{~B} & - & \text { MM no Rx. } \\ 12 & 1304 & 30.0 & 13.5 & 0.45 & 7.0 & 67 & \mathrm{~A} & - & \text { Idiopathic } \\ 13 & 2090 & 34.4 & 14.2 & 0.41 & 7.3 & 78 & \mathrm{~B} & - & \text { IHA } \\ 14 & 1335 & 28.1 & 13.0 & 0.46 & 6.6 & 71 & \mathrm{C} & - & \text { Macroglobulinemia } \\ & & & & & & & & & \\ 15 & 773 & 33.1 & 4.1 & 0.12 & 5.0 & 110 & \mathrm{~A} & - & \text { Tumor, on sulfa } \\ 16 & 1553 & 35.4 & 10.9 & 0.31 & 4.1 & 144 & \mathrm{~B} & - & \begin{array}{l}\text { AISA } \\ \text { Rh. Arth. } \\ 17\end{array} \\ & 1665 & 44.7 & 10.1 & 0.23 & 5.0 & 149 & \mathrm{~B} & \pm & \text { ? Felty's or drugs }\end{array}$

Symbols used in this Table: $\boldsymbol{v}$, decreased; $\wedge$, increased; ${ }^{*}$, segmented neutrophils per total myeloid cells in marrow; $\ddagger$, latest values calculated from 71 normal subjects; - -, no study obtained or calculation made.

Abbreviations used in this Table: AISA, acquired idiopathic sideroblastic anemia; AML, acute myeloblastic leukemia; DLE, disseminated lupus erythematosis; IHA, idiopathic hemolytic anemia; MM, multiple myeloma; N, neutrophilic cells; Rh. Arth., rheumatoid arthritis; segs., segmented neutrophils; P. A., pernicious anemia.

so the GTR was calculated from the CGP. Even if the TBGP were several times as large as the CGP, the GTR would still be below normal limits; thus decreased production seems highly probable in this patient.

Effective neutrophil production (GTR) was within the normal range, but near the lower limits thereof, in seven other patients with normal to values (Table I-B). It should be noted that in all of these seven patients, the TBGP was also normal but close to the lower limits of the normal range. In these patients with low normal TBGP and GTR values, the neutropenia seems to have resulted from borderline neutrophil production capability coupled with an increased proportion of neutrophils in marginal sites; i.e. a "shift neutropenia." The clinical disorders associated with this situation were highly variable; splenomegaly was present in only one patient.

\section{Neutropenia Characterized by Short $t_{2}^{\frac{1}{2}}$ VALUES}

The results obtained in the 18 patients with short $t$ values are shown in Table II.

Effective neutrophil production (GTR) was less than normal in five patients with short $t_{\frac{1}{3}}$ values (Table II- 
Bone marrow

\begin{tabular}{|c|c|c|c|c|c|c|}
\hline \multirow{3}{*}{$\frac{\text { Biopsy }}{\text { Cellularity }}$} & \multicolumn{4}{|c|}{ Aspiration } & & \\
\hline & \multirow{2}{*}{$\begin{array}{l}\text { Cellularity } \\
\text { and/or } \\
\text { comments }\end{array}$} & \multirow[b]{2}{*}{$\mathrm{M} / \mathrm{E}$} & \multirow{2}{*}{$\begin{array}{l}\text { Segs/total } \\
\text { myel.* }\end{array}$} & \multirow{2}{*}{$\begin{array}{c}\text { Myelocytes, } \\
\% \text { labeled } \\
\text { in vitro } \\
\text { with }{ }^{3} \mathrm{HTdR}\end{array}$} & \multicolumn{2}{|c|}{ Neut. reserves } \\
\hline & & & & & Endotoxin & Cortisol \\
\hline & \multicolumn{4}{|c|}{$\%$} & \multicolumn{2}{|c|}{$\Delta N / m m^{3}$} \\
\hline & & & $10-30$ & $19.2-27.5$ & $2400-10,000$ & $5100-9800$ \\
\hline - & $\wedge$ & 1.7 & 5.0 & 一 & 一 & - \\
\hline - & Blasts & 0.9 & 7.8 & - & 一 & 一 \\
\hline - & Normal & - & - & - & - & - \\
\hline - & - & - & - & - & - & - \\
\hline- & Blasts & 2.2 & 9.8 & - & 一 & - \\
\hline - & Normal & 17.5 & 27.6 & - & - & - \\
\hline Normal & $v$ & 1.3 & 3.8 & 29.1 & 973 & 1224 \\
\hline - & Normal & 12.4 & 36.5 & 26.0 & - & - \\
\hline$v$ & Normal & 3.3 & 27.3 & - & - & - \\
\hline Normal & Normal & 2.5 & 6.0 & - & - & - \\
\hline - & $\begin{array}{l}\text { Plasma } \\
\quad \text { cells } 34 \%\end{array}$ & 2.4 & 42.1 & - & - & - \\
\hline - & 一 & - & - & - & 一 & 一 \\
\hline Normal & Normal & 1.0 & 34.1 & - & - & 一 \\
\hline - & $\begin{array}{l}40 \% \\
\text { lymphs }\end{array}$ & 32.0 & 48.7 & 一 & - & - \\
\hline - & Normal & 5.4 & - & 一 & 736 & - \\
\hline $\boldsymbol{\wedge}$ & Normal & 1.0 & 22.2 & - & - & - \\
\hline$v$ & Normal & 0.6 & 24.3 & - & - & 1507 \\
\hline
\end{tabular}

A). In all of these patients, a very small TBGP was turning over more rapidly than normal but the marrow appeared to be unable to compensate by increasing effective cell production. Three of these patients were thought to have collagen vascular disease and two remain undiagnosed. Splenomegaly was present in three of the five patients.

Effective neutrophil production (GTR) was within the normal range in eight subjects with neutropenia and short $t_{t}$ values (Table II-B). In five of these patients, the GTR was about twice the normal mean value; all five had splenounegaly. The neutropenia in this group of patients appears to have resulted mainly from the rapid turnover of a small or low-normal TBGP and a marrow that could increase production only moderately. The clinical diagnosis in this group of patients varied widely. Splenomegaly was noted in five of these eight patients.

Effective neutrophil production (GTR) was increased above the normal $95 \%$ limits in five neutropenic patients with short $t$ values (Table II-C). Of considerable interest are the findings that in all five patients: (a) TBGP was well within normal limits; $(b)$ the CGP/TBGP ratio was less than 0.27 (a value rarely 
TABLE II

Neutropenic Patients with

\begin{tabular}{|c|c|c|c|c|c|c|c|c|c|}
\hline \multirow[b]{3}{*}{ Subject } & \multirow[b]{3}{*}{$N$} & \multicolumn{6}{|c|}{ Kinetic data } & \multirow{2}{*}{\multicolumn{2}{|c|}{ Clinical data }} \\
\hline & & \multirow[b]{2}{*}{ TBGP } & \multirow[b]{2}{*}{ CGP } & \multirow{2}{*}{$\begin{array}{l}\text { CGP/ } \\
\text { TBGP } \\
\text { ratio }\end{array}$} & \multirow[b]{2}{*}{$t_{\frac{1}{2}}$} & \multirow[b]{2}{*}{ GTR } & \multirow[b]{2}{*}{$\begin{array}{l}\text { Curve } \\
\text { type }\end{array}$} & & \\
\hline & & & & & & & & $\begin{array}{l}\text { Spleno- } \\
\text { megaly }\end{array}$ & Diagnosis \\
\hline & $\mathrm{N} / \mathrm{mm}^{3}$ & $N \times 1 c$ & $7 / \mathrm{kg}$ & & $h r$ & $\begin{array}{c}N / k g \text { per } \\
d a y \times 10^{7}\end{array}$ & & & \\
\hline \multicolumn{10}{|c|}{ Normal values } \\
\hline \multicolumn{2}{|c|}{ Mean .... } & 61 & 31 & 0.49 & 6.3 & 160 & & & \\
\hline \multicolumn{2}{|c|}{$95 \%$ limits } & $27-138$ & $13-49$ & $0.2-1$ & $4-10$ & $62-400$ & & & \\
\hline
\end{tabular}

Neutropenic patients with a short $t_{\frac{1}{3}}$ and decreased cell production (GTR)

$\begin{array}{llclllllll}18 & 956 & 5.7 & 5.2 & 0.91 & 3.0 & 33 & \text { A } & - & \text { Idiopathic } \\ 19 & 136 & 0.65 & 1.1 & - & 0.5 & 21 & \text { A } & + & \text { Felty's } \\ 20 & 544 & 3.6 & 4.0 & - & 2.3 & 26 & \text { B } & + & \text { ? DLE } \\ 21 & 297 & 10.8 & 1.7 & 0.16 & 3.3 & 56 & \text { C } & - & \text { Idiopathic } \\ 22 & 123 & 3.1 & 1.2 & 0.39 & 2.0 & 26 & \text { B } & + & \text { Felty's, DLE }\end{array}$

Neutropenic patients with a short $t_{\frac{1}{3}}$ and normal cell production (GTR)

$\begin{array}{rrrrrrrrrl}23 & 1018 & 17.4 & 5.2 & 0.28 & 1.0 & 289 & ? & + & \text { Cirrhosis } \\ 24 & 1288 & 30.6 & 12.4 & 0.40 & 2.7 & 189 & \mathrm{~A} & - & \text { Colo tick f. } \\ 25 & 440 & 22.7 & 2.2 & 0.10 & 1.3 & 290 & \mathrm{~A} & + & \text { Myelofibrosis } \\ 26 & 820 & 18.2 & 6.3 & 0.35 & 2.2 & 138 & \mathrm{~A} & - & \text { Idiopathic } \\ 27 & 1606 & 63.6 & 9.2 & 0.15 & 3.3 & 317 & \mathrm{~B} & + & \text { Weber Christian } \\ 28 & 2205 & 44.2 & 16.6 & 0.38 & 2.0 & 368 & \mathrm{~A} & + & \text { Cirrhosis } \\ 29 & 654 & 15.0 & 5.0 & 0.33 & 2.1 & 119 & \mathrm{~A} & - & \text { P. A. } \\ 30 & 2077 & 58.5 & 13.5 & 0.23 & 2.5 & 389 & \mathrm{~A} & + & \text { Felty's }\end{array}$

Neutropenic patients with a short $t_{\frac{1}{3}}$ and increased cell production (GTR)

\begin{tabular}{|c|c|c|c|c|c|c|c|c|c|}
\hline 31 & 2088 & 49.8 & 13.5 & 0.27 & 1.0 & 826 & A & - & Idiopathic \\
\hline 32 & 1181 & 88.1 & 6.6 & 0.07 & 3.0 & 488 & B & + & Cirrhosis \\
\hline 33 & 1351 & 118.0 & 10.8 & 0.06 & 1.8 & 1090 & $\mathrm{C}$ & + & Felty's \\
\hline 34 & 1873 & 106.1 & 14.4 & 0.14 & 3.0 & 588 & A & + & Cirrhosis \\
\hline 35 & 1650 & 46.2 & 10.2 & 0.22 & 1.0 & 768 & C & + & Cirrhosis \\
\hline
\end{tabular}

See Table I footnote for explanation of abbreviations.

seen in normal subjects-see below); and (c) four of the five subjects had splenomegaly associated with hepatic cirrhosis or Felty's syndrome. It appears that increased blood neutrophil turnover and marrow production, coupled with margination of neutrophils and perhaps splenic sequestration, are important pathogenic factors in this group.

Possible indirect measurements of neutrophil turnover rate

\section{Serum Lysozyme Levels in NeUtropenic Patients}

Since it has been suggested that serum lysozyme levels may correlate with neutrophil turnover rate, a correlation between GTR and serum lysozyme levels was sought in neutropenic patients. It can be seen in Fig. 1-A that the serum lysozyme level in 20 normal subjects ranged from $30-65 \mu \mathrm{g} / \mathrm{ml}$ and that the lysozyme levels in the neutropenic patients were either normal or somewhat increased. There were three patients with elevated GTR in whom the serum lysozyme was measured. Of these, two were within normal limits and the third was only somewhat elevated. In addition, it is evident in Fig. 1-B that even though the GTR ranged from 20 to $1100 \times 10^{7} \mathrm{~N} / \mathrm{kg} /$ day (that is from $1 / 8$ to 7 times the normal mean) there was no correlation between serum lysozyme levels and GTR in the 13 patients so studied. The lack of correlation existed whether the GTR was calculated from the TBGP or from the CGP.

Since lysozyme is only found in the urine of some patients with leukemia, no serious attempt to correlate GTR with urinary lysozyme was made. In the several neutropenic patients surveyed there was no lysozyme present in the urine. 


\begin{tabular}{|c|c|c|c|c|c|c|}
\hline \multirow{3}{*}{$\frac{\text { Biopsy }}{\text { Cellularity }}$} & \multicolumn{4}{|c|}{$\begin{array}{l}\text { Bone marrow } \\
\text { Aspiration }\end{array}$} & & \\
\hline & \multirow{2}{*}{$\begin{array}{l}\text { Cellularity } \\
\text { and/or } \\
\text { comments }\end{array}$} & \multirow{2}{*}{$\begin{array}{l}M / E \\
\text { ratio }\end{array}$} & \multirow{2}{*}{$\begin{array}{l}\text { Segs/total } \\
\text { myel.* }\end{array}$} & \multirow{2}{*}{$\begin{array}{c}\text { Myelocytes, } \\
\% \text { labeled } \\
\text { in vitro } \\
\text { with }{ }^{3} \mathrm{HTdR}\end{array}$} & \multicolumn{2}{|c|}{ Neut. reserves } \\
\hline & & & & & Endotoxin & Cortisol \\
\hline & \multicolumn{4}{|c|}{$\%$} & \multicolumn{2}{|c|}{$\Delta N / m m^{3}$} \\
\hline & & & $10-30$ & $19.2-27.5$ & $2400-10,000$ & $5100-9800$ \\
\hline - & Normal & 4.6 & 10.7 & - & - & - \\
\hline$\wedge$ & Normal & 1.1 & 1.1 & 26.4 & 978 & 175 \\
\hline$\wedge$ & Normal & 9.0 & 12.7 & - & - & 1086 \\
\hline - & Normal & 2.5 & 17.9 & 33.6 & - & 371 \\
\hline - & Normal & 1.3 & 1.3 & - & 1147 & 61 \\
\hline - & $\wedge$ & 0.7 & 46.2 & - & - & - \\
\hline- & - & - & - & - & - & - \\
\hline$\wedge$, fibrosis & $\wedge$ & 0.17 & 4.4 & - & - & - \\
\hline - & Normal & 1.6 & 33.0 & 20.5 & 2005 & 4594 \\
\hline - & Normal & 1.4 & 4.9 & - & - & 0 \\
\hline - & Normal & 3.4 & 20.4 & 23.0 & - & 590 \\
\hline- & $\wedge$ & 0.8 & 13.7 & 27.3 & - & - \\
\hline - & Normal & 1.3 & 53.0 & 39.0 & - & 3631 \\
\hline - & $\wedge$ & 1.1 & 18.6 & - & - & - \\
\hline - & Normal & 0.9 & 19.0 & - & - & - \\
\hline - & $\wedge$ & 4.4 & 15.1 & 27.1 & - & 513 \\
\hline Normal & Normal & 1.3 & 54.3 & 31.0 & - & 1505 \\
\hline Normal & Normal & 6.7 & 14.1 & 26.0 & - & 344 \\
\hline
\end{tabular}

\section{Urinary Uric ACD Levels in NeUtropenic Patients}

Quantitative 24-hr urinary uric acid excretion was measured in nine patients with neutropenia in whom GTR values ranged from $15-1090 \mathrm{~N} / \mathrm{kg}$ per day. In patients with low GTR values, normal or elevated uric acid excretion was noted while in patients with elevated GTR values, uric acid excretion was normal. In short, no correlation between GTR and uric acid excretion was demonstrable.

\section{Bone Marrow Cellularity and Differential} Counts in Neutropenic Patients

In the hope that marrow cellularity, differential counts, or in vitro ${ }^{8} \mathrm{HTdR}$ uptake by marrow cells might correlate with aberrations of blood neutrophil kinetics, bone marrow biopsies, and aspirations were performed as often as possible in the patients studied.
Marrow biopsy cellularity. Bone marrow biopsies were obtained in 12 of the neutropenic patients studied. Impressions as to their cellularity are included in Tables I and II. No patients with short $t$ values showed hypocellular marrow by biopsy (Table II), but there was no clear correlation between biopsy cellularity and blood GTR.

Marrow aspirations. No correlation between the marrow differential counts (e.g. percentage of myeloid cells that were mature segs, etc.) and GTR, $t_{1}$, presence of splenomegaly or clinical diagnosis could be demonstrated.

${ }^{3} H T d R$ uptake by marrow myeloid cells in vitro. A comparison of in vitro ${ }^{3} \mathrm{HTdR}$-labeling index (per cent myelocytes labeled after $1 \mathrm{hr}$ incubation) in marrow specimens from 14 neutropenic patients with results obtained in four normal marrows revealed a suggestive increase in labeling index in marrows from patients 


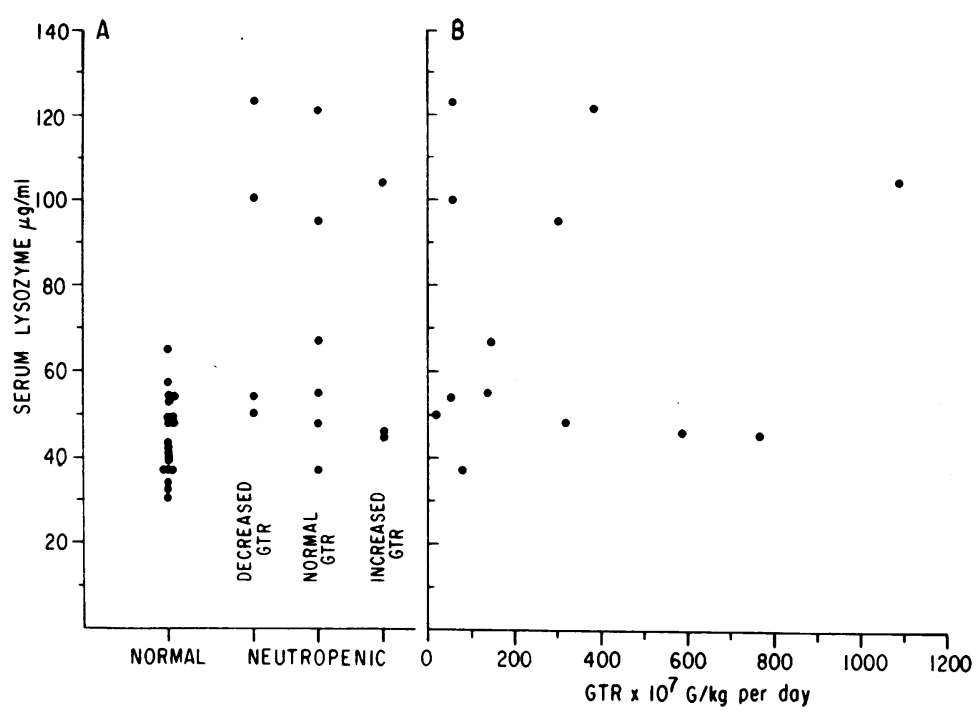

Figure 1 In A, serum lysozyme concentration (method relates the sample to egg white lysozyme standard) in normal subjects and neutropenic patients in whom a normal, increased or decreased neutrophil turnover rater (GTR) was demonstrated. B shows the relationship between the serum lysozyme concentration and the GTR in neutropenic patients.

with short $t_{\frac{1}{2}}$ values (Fig. 2). Nevertheless, no correlation between labeling index and GTR was demonstrable and no clear identification of a particular group of neutropenic patients (e.g. neutropenics with a short $t_{1}$ and increased GTR) was possible.

\section{Marrow Neutrophil Reserve in NeutrophiL Patients}

To evaluate marrow neutrophil reserves in these neutropenic patients the change in blood neutrophil count after the injection of endotoxin or cortisol was studied. The results are included in Tables I and II and can be compared with results in normal subjects.

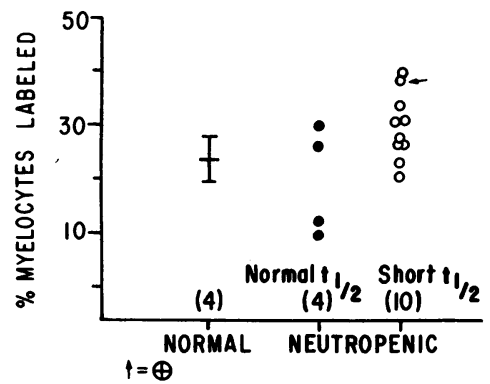

FIgURE 2 A comparison of in vitro, ${ }^{3} \mathrm{HTdR}$-labeling index (per cent myelocytes labeled) in marrow from four normal subjects and 14 patients with neutropenia. Open circles $(O)$ refer to patients with short $t_{\frac{1}{2}}$ values, solid circles (•) patients with normal $t_{\frac{1}{2}}$ values. $\oplus$ indicates one subject with a normal $t_{\frac{1}{2}}$ and neutropenia but with incomplete kinetic studies who is not included in Table I.
Although only 13 patients with complete kinetic studies were evaluated with cortisol and/or endotoxin tolerance tests, it is evident that none of them was able to mobilize a normal number of neutrophils into the blood from the marrow. In addition, neutrophil mobilizing ability seemed unrelated to the blood neutrophil $t_{2}$, GTR, marrow cellularity, or clinical diagnosis.

Blood neutrophil pool size and cell distribution in the CGP and MGP in neutropenic patients

When the TBGP values and the blood neutrophil concentrations in these 35 neutropenic patients are plotted (Fig. 3) several interesting facts become apparent. It is evident that normal $t_{\frac{1}{3}}$ values (solid circles) were found in patients with both mild and severe neutropenia. Similarly, short $t_{\frac{1}{2}}$ values were found at all levels of neutropenia (open circles). It can also be seen that in 19 of the 35 patients with neutropenia the TBGP value was normal, that is greater than $27 \times 10^{7} \mathrm{~N} / \mathrm{kg}$, the lower limit of the normal range, and that in most of the neutropenic patients with neutrophil count over 1,000 cells $/ \mathrm{mm}^{3}$ (17 of 20 patients) the TBGP value was normal while in only 2 of 15 patients with a neutrophil concentration less than 1,000 cells $/ \mathrm{mm}^{3}$ was the TBGP normal. From this is appears that in subjects with minimal to moderate neutropenia $(>1,000$ neutrophils $/ \mathrm{mm}^{3}$ ) the neutropenia may often reflect a shift of cells into marginal sites, a "shift neutropenia."

Further evidence that the neutropenia in these 19 patients reflected an intravascular shift of cells into 
marginal sites may be found in the fact that in 10 of the 19, the neutrophil counts fluctuated from neutropenic to normal values. It was not possible to exercise these patients in an attempt to demarginate cells. However, one patient (case 28) had several convulsions and the neutrophil concentration increased 1300 cells $/ \mathrm{mm}^{3}$ above her previous level during the $15 \mathrm{~min}$ after seizure.

In eight neutropenic patients in whom it was felt epinephrine infusion could be tolerated, a sudden transient increase in neutrophil concentration was obtained (rise and return to control levels in less than $15 \mathrm{~min}$ ). The increase ranged from 60 to 2120 neutrophils $/ \mathrm{mm}^{3}$ and tended to be large if the TBGP was large. However, there was no clear difference in the epinephrine response in patients who had a shift neutropenia and those with a true neutropenia.

The proportion of the TBGP present in the CGP/ TBGP ratio) in patients with "shift neutropenia" $($ TBGP $>27)$ and true neutropenia (TBGP $<27$ ) can be compared with the distribution in normal subjects. In patients with "shift neutropenia" the CGP/TBGP ratio tended to be lower than in normal subjects and ranged from 0.06 to 0.46 . In eight of these patients, the CGP/TBGP ratio was $<0.25$, the lower limit of the normal range. The distribution of cells in the true neutropenic patients did not differ from that seen in normal subjects.

It is of additional interest that although patients without detected splenomegaly may have short $t_{1}$ values, 12 of 14 patients with splenomegaly had short t values (see Table II). Also in the nine subjects with TBGP

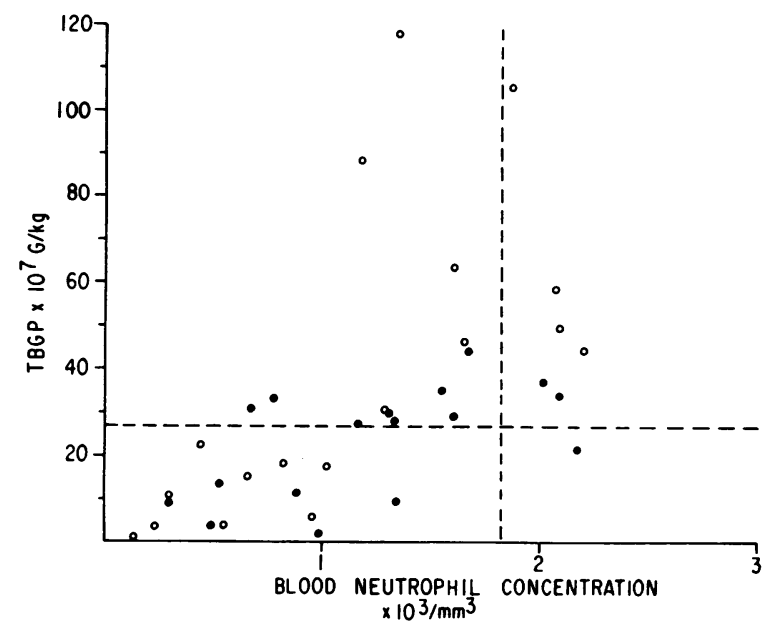

FIgURE 3 The relationship of TBGP size and blood neutrophil concentration in 35 neutropenic patients studied by means of the in vitro $\mathrm{DF}^{32} \mathrm{P}$ method. The dashed lines indicate the lower portion of the normal range of TBGP and blood neutrophil concentration. Solid circles $(\bullet)$ indicate neutropenic patients with normal $t_{1}$ values. Open circles $(O)$ indicate neutropenic patients with short $t_{\frac{1}{2}}$ values.

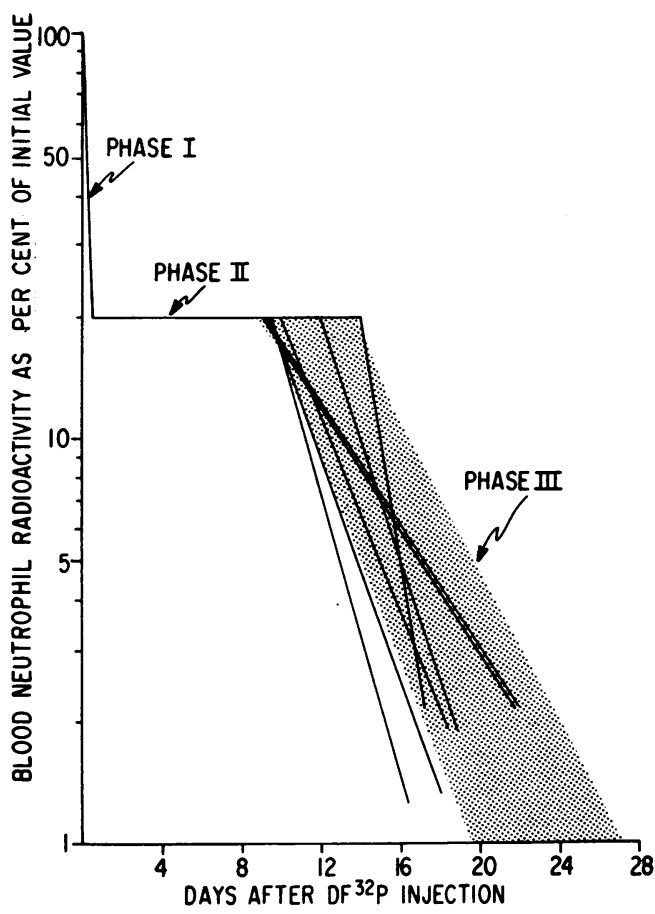

FIGURE 4 In vivo $\mathrm{DF}^{32} \mathrm{P}$ curves in neutropenic patients as compared with normals. The shaded area delimits the range of normal values obtained in 21 normal subjects. The seven studies done on neutropenic subjects are plotted in an idealized form to show the duration of phases I and II and the $t_{\frac{1}{2}}$ of phase III.

values greater than 40 (Fig. 3), eight had short tis values and seven of these eight had splenomegaly. From this it can be argued that in such patients, rapid sequestration and removal of labeled cells from the blood during the 10-20 min needed to infuse them could have resulted in erroneously high TBGP values. However, if it is assumed that the $t_{1}$ measured in a subject also describes the rate of removal of cells during the infusion period, a correction can be made in the TBGP calculation for the error introduced by ignoring this removal. (Ordinarily this error is very small $(<5 \%)$ when the $\mathrm{t}_{\frac{1}{2}}$ is normal). Correction of the TBGP values in these eight patients did not bring the TBGP into the neutropenic range.

\section{In vivo $\mathrm{DF}^{32} \mathrm{P}$-kinetic studies}

In an attempt to ascertain whether the pattern of neutrophil production in the marrow of neutropenic patients is different in decreased production neutropenia as compared with increased utilization and turnover states, several patients were given $\mathrm{DF}^{32} \mathrm{P}$ intravenously after the kinetic studies already described. In these in vivo-labeling studies, both blood and marrow neutrophilic cells are labeled and as the labeled blood cells leave the circulation (phase $I$ in Fig. 4) they are re- 
TABLE III

In Vivo D $F^{32} P$ Kinetic Studies in Neutropenic Patients

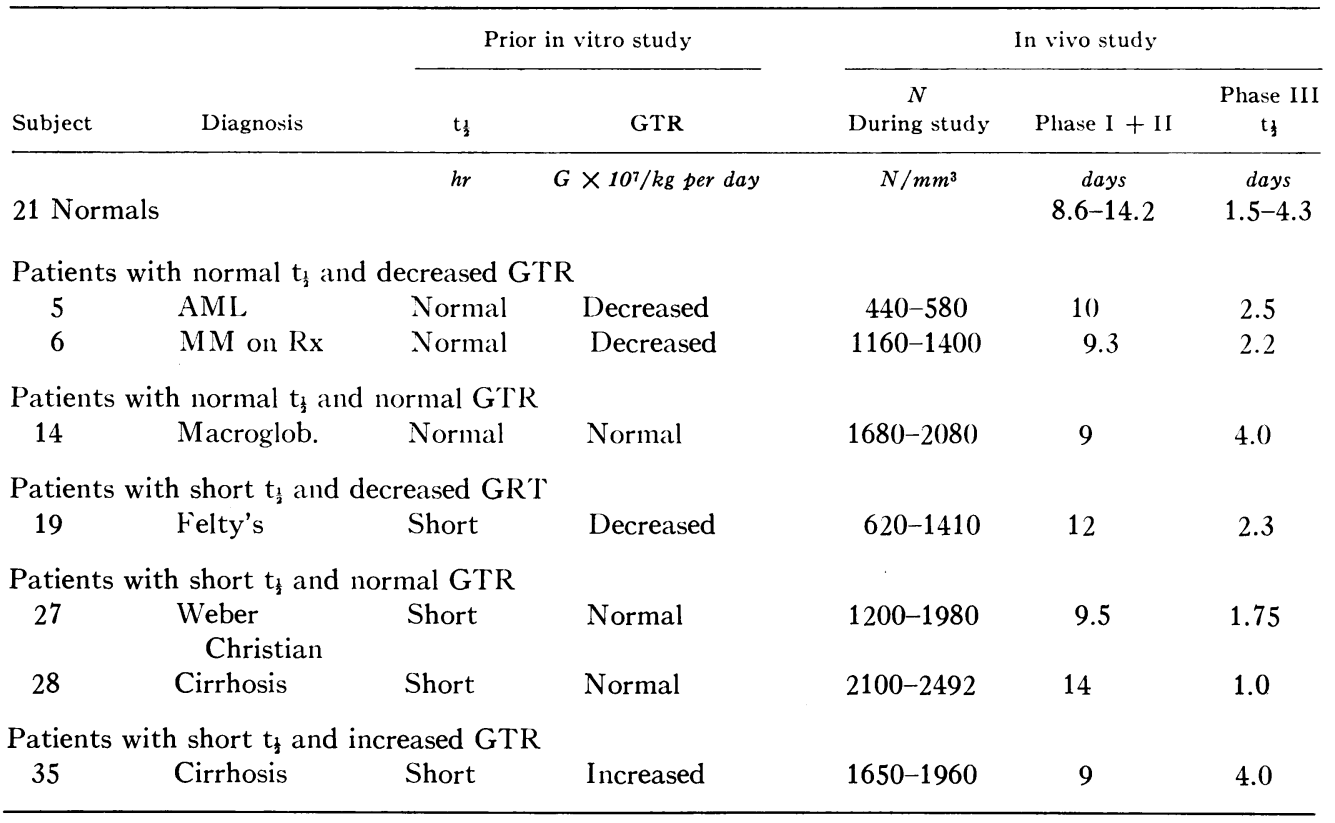

placed by labeled cells from the marrow (phase II) (10). The time span over which the blood neutrophil radioactivity remains fairly stable is referred to as phase I plus II and gives a measure of the time required for myelocytes to mature in the marrow and enter the blood $(9,10)$. Though it has not gained wide acceptance, the $t_{\frac{1}{3}}$ of phase III is believed by us to reflect the generation time of the myelocyte compartment in the marrow $(3,9,10)$.

It can be seen in Fig. 4 and Table III that the seven in vivo $\mathrm{DF}^{32} \mathrm{P}$-kinetic studies carried out in neutropenic patients did not differ significantly from the results previously encountered in 21 normal volunteers. Even though one or two patients from each kinetic class were studied in this way, no difference in marrow to blood transit time (phase I + II) or in marrow myelocyte generation time (phase III $\mathrm{t}_{\frac{1}{3}}$ ) could be demonstrated. Even in neutropenic patients with short time and increased blood GTR, the myelocyte to blood transit time and the myelocyte generation time were the same as in patients with purely decreased cell production (normal $\mathrm{t}_{\frac{1}{2}}$ and low GTR).

\section{DISCUSSION}

From these studies it seems that neutropenia may be associated with decreased neutrophil production, an intravascular shift of cells, apparently to marginal sites, or rapid removal of neutrophils from the blood. Furthermore, in a patient with neutropenia, more than one of these pathogenic mechanisms may be operative at the same time.

The category of simple decreased-production neutropenia consists of patients with a low neutrophil turnover rate, a small blood neutrophil pool and normal $t_{\frac{1}{3}}$ values (Table I-A). Several of these patients suffered from hematologic malignancies with marrow infiltration by abnormal cells; in several there was well-documented marrow suppression by drugs while in three or four the clinical diagnosis remains uncertain. In this group of patients neutropenia appears to be the result of a simple marrow production deficit.

Altered intravascular distribution of neutrophils appears to explain the neutropenia in a group of patients with low normal TBGP and GTR values and a normal $t_{1}$ (Table I-B). The degree of cell redistribution as expressed by the CGP/TBGP ratio was less than the normal mean value of 0.46 in these patients but within the rather wide normal range $(0.23-1.00)$ in all but two. The patients in this group suffered from a variety of clinical diseases but splenomegaly was an uncommon finding. It should be noted that the degree of neutropenia in these patients was mild in that all but one had neutrophil concentrations greater than $1,000 / \mathrm{mm}^{3}$. Also it should be noted that although epinephrine infusion will mobilize some marginated cells in neutropenic patients just as it does in normal subjects $(2,14)$, it was not possible to differentiate altered distribution neutropenia from other neutropenic patients on the basis of this test. 
The remainder of the patients studied appeared to have neutropenia of more complex pathogenesis. All exhibited an accelerated fractional turnover rate of the blood neutrophil pool; i.e., a short $t_{1}$ value, coupled with varying degrees of marrow production and altered cell distribution (Table II). Two-thirds of these patients had splenomegaly.

Increased destruction seems to explain the neutropenia found in a group of patients with Felty's syndrome or hepatic cirrhosis (Table II-C). These patients had short $t_{1}$ values, normal TBGP values, and elevated GTR values. In addition, a markedly altered intravascular cell distribution (CGP/TBGP ratio less than 0.27 ) was present in all. This presumably reflects sequestration in the spleen since splenomegaly was present in five of the six patients. As with the simple "shift" neutropenias mentioned above (Table I-B), the neutropenia was mild in that all subjects had neutrophil counts greater than 1,000 cells $/ \mathrm{mm}^{3}$. This group of patients appear to be analogous to patients with wellcompensated hemolytic disease except that a shift of neutrophils out of the CGP into marginal sites makes them seem neutropenic even though the TBGP is normal. An alternative explanation for the findings in this group of patients is that the TBGP values are erroneously high. If this were the case, a normal TBGP coupled with a short $t_{t}$ would result in calculation of a high GTR when in fact the GTR may be normal or low. From the data collected this possibility cannot be excluded since there is no independent, alternative method for measuring TBGP and/or MGP size. However, if one calculates the GTR from the CGP rather than from the TBGP in these patients, the GTR values are still abnormal when compared to similarly calculated values for normal subjects. Such a calculation almost certainly underestimates the true GTR since no allowance for cells in the MGP is made.

The $t$ was shorter than normal in two other patient groups (Table II-A and B). In spite of the fact that the TBGP was turning over rapidly in these subjects the blood neutrophil turnover rate was less than normal (Table II-A) or within the normal range (Table IIB), apparently depending primarily on the size of the TBGP. Thus short neutrophil survival in the blood combined with inadequate marrow compensation appears to be the pathogenetic mechanism of the neutropenia in these patients. These two patient groups appear to be analogous to patients with hemolytic anemia who are unable to increase marrow production enough to compensate for accelerated blood cell removal. No patient with what might be called "ineffective granulocytopoiesis" was recognized in these studies. However, a cellular marrow biopsy coupled with a short $t$ and yet a low blood GTR in two patients (Table II-A) sug- gests this possibility. Since no method for measuring marrow neutrophil production capability has yet been developed, ineffective granulocytopoiesis cannot be proven. The one patient with pernicious anemia studied had a normal GTR and a short $\mathrm{t}_{\frac{1}{2}}$ (Table II-B).

Similar studies of blood neutrophil kinetics in small groups of patients with neutropenia, often associated with a particular disease such as hepatic cirrhosis (15, 16), rheumatoid arthritis (17), or acute leukemia (18), had been reported by other workers. There is general agreement concerning the kinetic classification groups just described except that the "shift neutropenia" group documented here (Table I-B) has not been reported previously. If the TBGP measurements in certain patients were artifactually high because of rapid removal of infused cells in some neutropenic patients it is clear that this would produce the picture of shift neutropenia. We do not think this is the case here because: (a) when the TBGP size is compared with the blood neutrophil concentration in all subjects studied, there is reasonable concordance between the two measurements in all but three subjects (Fig. 3); (b) there is no preponderance of $B$ and $C$ type curves in the "shift neutropenia" patients as compared to the patients with true neutropenia. If the shift neutropenia were artifactual as a result of rapid removal of labeled cells from the blood, one might expect this to be the case.

It has been suggested or implied that kinetic parameters such as the tor GTR may correlate with clinical tests such as marrow cellularity, serum vitamin $B_{12-}$ binding capacity, or serum or urinary lysozyme levels. However, no proof of such correlation has yet appeared. Perhaps the greatest hope for such a clinically useful test has been for the lysozyme determination. Since lysozyme has been demonstrated histochemically in neutrophils (19); since high levels of lysozyme have been found in the serum of patients with CML (20); and since CML patients have been shown to have high GTRs (21), it has logically been assumed that such a correlation might exist. However, it has also been demonstrated histochemically that lysozyme is present in monocytes and in neutrophil precursors back to and including the promyelocytes (19). Furthermore, the highest levels of lysozyme are found in the sera and urine of patients with monocytic leukemia $(11,22)$. Thus, there are equally good reasons to suspect that serum lysozyme might correlate with monocyte turnover, or more likely some combination of mature neutrophil, neutrophil precursor, and monocyte turnover. In any case, in the present studies, no correlation between serum lysozyme levels and the blood neutrophil turnover rate, (calculated from the TBGP and $t_{2}$ ) could be demonstrated even though the GTR varied from very low levels to about seven times the normal 


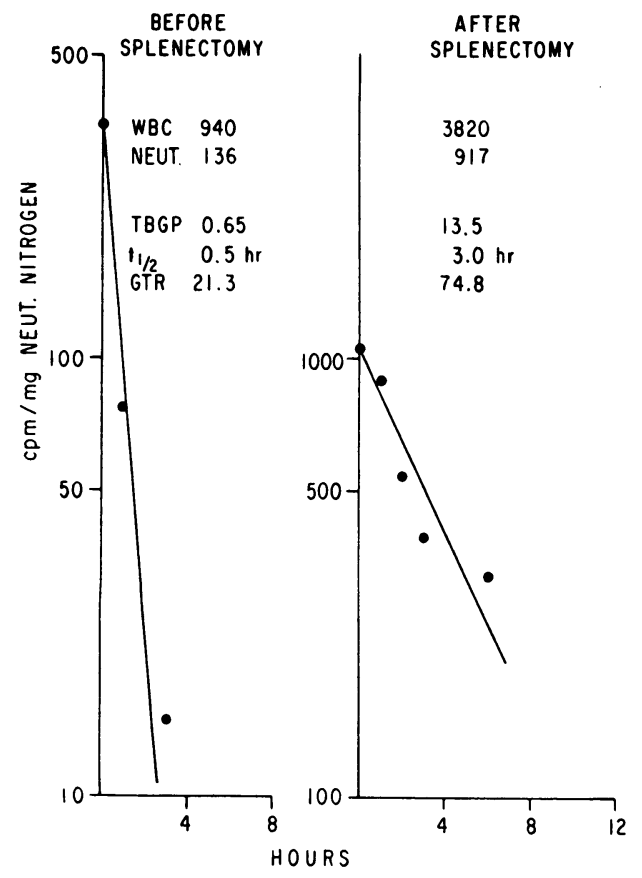

FIgURE 5 Neutrophil kinetics in a patient with Felty's syndrome before and after splenectomy. TBGP $\times 10^{7}$ cells/ $\mathrm{Kg}$ body weight and GTR $\times 10^{7}$ cells $/ \mathrm{kg} /$ day. Before splenectomy the half disappearance time $\left(t_{\frac{1}{3}}\right)$ of neutrophils is $\frac{1}{2} \mathrm{hr}$ and the neutrophil turnover rate was low (normal is $62-400)$. After splenectomy the $t_{\frac{1}{2}}$ is still below normal limits but is longer than before, and the GTR is within normal limits.

mean value. To eliminate the possibility that the GTR values might be erroneous because of artifactually high TBGP values, the GTR values were also calculated from CGP values. There was still no correlation between lysozyme levels and blood neutrophil turnover.

The lack of correlation of neutrophil turnover rate with marrow cellularity as estimated from biopsy or aspiration specimens is not surprising since the vagaries of sampling the marrow with these methods is wellknown. Perhaps measurement of marrow granulocyte mass (23) in conjunction with blood neutrophil kinetic studies might reveal a more clear relationship between production capacity and blood GTR. Such studies have been reported for the megakaryocyte-platelet system (24) and would be of great interest. In this regard it is worth noting that in no patient with a short $t_{3}$ value was a hypocellular marrow seen. However, a puzzling and unexplained finding is that even in neutropenic patients with short tis values and apparently normal or hypercellular marrows, the ability to release marrow neutrophils into the blood in response to either cortisol or endotoxin was clearly less than normal. In no case did the increase in blood neutrophil count after such stimulation reach normal values (Tables I and II).
The essentially normal in vivo-kinetic curves obtained in neutropenic patients (Fig. 4) have interesting implications in regard to the control of marrow neutrophil production. Possible mechanisms by which the marrow might attempt to compensate for neutropenia and increase cell output are: $(a)$ an increased rate of differentiation and maturation of neutrophils with early release into the blood. Such an event should result in a short phase I + II (i.e. myelocyte to blood transit time). Sacchetti, Boccaccio, Ponassi, and Morra have reported short phase I + II values in patients made neutropenic by recent chemotherapy $(25) ;(b)$ an increased rate of neutrophil precursor cell division and shortening of generation time. This mechanism should result in a short $t_{\frac{1}{2}}$ of phase III (i.e. myelocyte turnover rate) and possibly, an increase in marrow myelocyte-labeling index with ${ }^{3} \mathrm{HTdR} ;(c)$ an increase in the number of uncommitted stem cells entering the myeloid channel thereby increasing cell production capability; $(d)$ decreased loss of cells into the hypothetical myelocyte "sink"; (e) combinations of these several mechanisms.

If it is assumed that at least in those neutropenic patients with short $t$ crease cell production is being made, then the essentially normal in vivo-kinetic curve (Fig. 4 and Table III) provide evidence against the likelihood that $(a)$ and (b) are major compensatory mechanisms. From this and the fact that the marrow seemed normal or hypercellular in many patients (Table II), mechanisms (c) and perhaps $(d)$ seem most likely. Mechanism $(d)$ is hypothetical and highly controversial and there is currently no way to rule it in or out. Mechanism (c) seems a likely possibility since evidence from spleen colony studies (26), in vitro-marrow culture work (27), and model studies of feedback control of granulocytopoiesis (28) all suggest this as a key point of feedback control. Since in vivo- $\mathrm{DF}^{32} \mathrm{P}$ curves only measure certain time parameters of cell flow in the marrow, measurements of marrow mass will be necessary to prove this.

Although the $\mathrm{DF}^{32} \mathrm{P}$ studies provide a pathophysiologic classification of neutropenia it is unfortunate that none of the clinical tests appear to be useful in placing patients in one of the several categories. The need for tests analogous to the fecal urobilinogen and serum haptoglobin as measures of red cell breakdown remains. The clinical utility of a single test correlating well with rapid blood neutrophil removal is illustrated in Fig. 5. In this patient with severe neutropenia, frequent infections and a fast $t_{2}$, splenectomy resulted in marked clinical and moderate kinetic improvement. A simple test that could replace kinetic studies would be most helpful in management of such patients. 


\section{ACKNOWLEDGMENTS}

This investigation was supported by research grant AM04489 and training grant AM-5098 from the National Institute of Arthritis and Metabolic Diseases, and a grant FR00064 from the National Institutes of Health, Division of Research Facilities and Resources, Bethesda, Md.

\section{REFERENCES}

1. Mauer, A. M., J. W. Athens, H. Ashenbrucker, G. E. Cartwright, and M. M. Wintrobe. 1961. Leukokinetic studies. II. A method for labeling granulocytes in vitro with radioactive diisopropylfluorophosphate $\left(\mathrm{DFP}^{32}\right)$. J. Clin. Invest. 39: 1481.

2. Athens, J. W., O. P. Haab, S. O. Raab, A. M. Mauer, H. Ashenbrucker, G. E. Cartwright, and M. M. Wintrobe. 1961. Leukokinetic studies. IV. The total blood, circulating and marginal granulocyte pools and the granulocyte turnover rate in normal subjects. J. Clin. Invest. 40: 989.

3. Bishop, C. R., and J. W. Athens. 1970. Studies of granulocytopoiesis in abnormal conditions. In Hemopoietic Cellular Proliferation. F. Stohlman, Jr., editor. Grune \& Stratton, Inc., New York. 229.

4. Athens, J. W. 1969. Granulocyte kinetics in health and disease. Human tumor cell kinetics. Nat. Cancer Inst. Monogr. 30: 135.

5. Bishop, C. R., and J. W. Athens. 1969. Leukokinetic studies in neutropenic patients. J. Clin. Invest. 48: 8a. (Abstr.)

6. Bishop, C. R., and J. W. Athens. 1970. A kinetic classification of neutropenia based on half disappearence time (T $\frac{1}{2}$ ) and granulocyte turnover rate (GTR). Clin. Res. 18: 175 .

7. Gagon, T. E., J. W. Athens, D. R. Boggs, and G. E. Cartwright. 1966. An evaluation of the variance of the leukocyte counts as performed with the hemocytometer, Coulter and Fisher instruments. Amer. J. Clin. Pathol. 46: 684

8. Orfanakis, N. G., R. E. Ostlund, C. R. Bishop, and J. W. Athens. 1970. Normal blood leukocyte concentration values. Amer. J. Clin. Pathol. 53: 647.

9. Warner, H. R., and J. W. Athens. 1964. An analysis of granulocyte kinetics in blood and bone marrow. Ann. N. Y. Acad. Sci. 113: 523.

10. Cartwright, G. E., J. W. Athens, and M. M. Wintrobe. 1964. The kinetics of granulopoiesis in normal man. Blood J. Hematol. 24: 780 .

11. Osserman, E. F., and D. P. Lawlor. 1966. Serum and urinary lysozyme (Muramidase) in monocytic and monomyelocytic leukemia. J. Exp. Med. 124: 921.

12. Kingsley, D. M. 1937. Polychromed methylene blue as constituant of Romanowsky stains. J. Lab. Clin. Med. 22: 736.

13. Praetorius, E. 1949. An enzymatic method for the de. termination of uric acid by ultraviolet spectrophotometry. Scand. J. Clin. Lab. Invest. 1: 222.
14. Athens, J. W., S. O. Raab, O. P. Haab, A. M. Mauer, H. Ashenbrucker, G. E. Cartwright, and M. M. Wintrobe. 1961. Leukokinetic Studies. III. The distribution of granulocytes in the blood of normal subjects. J. Clin. Invest. 40: 159.

15. Reed, I. L., P. Barry, H. Wong, and M. S. Greenberg. 1966. Disappearance rates of circulating granulocytes in cirrhosis. XI ${ }^{\text {th }}$ Congress of the International Society of Haematology. 26. (Abstr.)

16. Greenberg, M. S., B. Zanger, and H. Wong. 1967. Studies in granulocytopenic subjects. Blood J. Hematol. 30: 891. (Abstr.)

17. Brubaker, L. H., and W. S. Irvin. 1970. Mechanisms of neutropenia in rheumatoid arthritis. J. Clin. Invest. 49: 13a. (Abstr.)

18. Perry, S. 1968. Leukocyte kinetics in leukemia. In Proceedings of the International Conference on LeukemiaLymphoma. Chris J. D. Zarafonetis, editor. Lea \& Febiger, Philadelphia. 229.

19. Briggs, R. S., P. E. Perillie, and S. C. Finch. 1966. Lysozyme in bone marrow and peripheral blood cells. $J$. Histochem. Cytochem. 14: 167.

20. Perillie, P. E., S. S. Kaplan, E. Tefkowitz, W. Rogaway, and S. C. Finch. 1968. Studies of muramidase (lysozyme) in leukemia. J. Amer. Med. Ass. 203: 317.

22. Wiernik, P. H., and A. A. Serpick. 1969. Clinical sigH. Ashenbrucker, G. E. Cartwright, and M. M. Wintrobe. 1965. Leukokinetic Studies. X. Blood granulocyte kinetics in chronic myelocytic leukemia. J. Clin. Invest. 44: 765 .

22. Wiernik, P. H., and A. A. Serpick. 1969. Clinical significance of serum and urinary muramidase activity in leukemia and other hematologic malignancies. Amer. J. Med. 46: 330 .

23. Donohue, D. M., B. W. Gabrio, and C. A. Finch. 1958. Quantitative measurement of hematopoietic cells of the marrow. J. Clin. Invest. $37: 1564$.

24. Harker, L. A. 1968. Megakarocyte quantitation. J. Clin. Invest. $47: 452$.

25. Sacchetti, C., P. Boccaccio, A. Ponassi, L. Morra. 1965. Neutrophilic leukocyte reserve of the bone marrow. 1) "In vivo" detection and quantitation with $\mathrm{DFP}^{32}$. Minerva Nucl. 9: 55 .

26. McCulloch, E. A., M. W. Thompson, L. Siminovitch, and J. E. Till. 1970. Effects of bacterial endotoxin on hemopoietic colony-forming cells in the spleens of normal mice and mice of genotype $\mathrm{S} 1 / \mathrm{S} 1^{\mathrm{d}}$. Cell Tissue Kinet. 3: 47.

27. Robinson, W. A., and B. L. Pike. 1970. Colony growth of human bone marrow cells in vitro. In Hemopoietic Cellular Proliferation. Frederick Stohlman, Jr., editor. Grune \& Stratton, Inc., New York. 249.

28. Morley, A., E. A. King-Smith, and F. Stohlman, Jr. 1970. The oscillatory nature of hemopoiesis. In Hemopoietic Cellular Proliferation. Frederick Stohlman, Jr., editor. Grune \& Stratton, Inc., New York. 3. 